\title{
Wild pollinators enhance oilseed rape yield in small-holder farming systems in China
}

\author{
Yi Zou ${ }^{1,2}{ }^{\mathbb{D}}$, Haijun Xiao ${ }^{3 *}$, Felix J. J. A. Bianchi ${ }^{4}$, Frank Jauker ${ }^{5}$, Shudong Luo ${ }^{6}$ and Wopke van der Werf ${ }^{1}$
}

\begin{abstract}
Background: Insect pollinators play an important role in crop pollination, but the relative contribution of wild pollinators and honey bees to pollination is currently under debate. There is virtually no information available on the strength of pollination services and the identity of pollination service providers from Asian smallholder farming systems, where fields are small, and variation among fields is high. We established 18 winter oilseed rape (Brassica napus L.) fields along a large geographical gradient in Jiangxi province in China. In each field, oilseed rape plants were grown in closed cages that excluded pollinators and open cages that allowed pollinator access. The pollinator community was sampled by pan traps for the entire oilseed rape blooming period.

Results: Oilseed rape plants from which insect pollinators were excluded had on average 38\% lower seed set, $17 \%$ lower fruit set and 12\% lower yield per plant, but the seeds were 17\% heavier, and the caged plants had 28\% more flowers and $18 \%$ higher aboveground vegetative biomass than plants with pollinator access. Oilseed rape plants thus compensate for pollination deficit by producing heavier seeds and more flowers. Regression analysis indicated that local abundance and diversity of wild pollinators were positively associated with seed set and yield/straw ratio, while honey bee abundance was not related to yield parameters.

Conclusions: Wild pollinator abundance and diversity contribute to oilseed rape yield by enhancing plant resource allocation to seeds rather than to above-ground biomass. This study highlights the importance of the conservation of wild pollinators to support oilseed rape production in small-holder farming systems in China.
\end{abstract}

Keywords: Ecosystem services, Canola, Compensation, Honey bee, Pollination, Pollinator diversity, Wild bee

\section{Background}

A wide range of agricultural crops depend on pollination by insects [1]. The decline of pollinators in terms of abundance and species richness has caused great concern about the risk of a deterioration of crop pollination and the associated crop production [2-6]. Potential drivers for the loss of wild pollinators include habitat loss and fragmentation, insecticides, pathogens, invasive species, climate change and the interactions between them [5]. The consequences of the decline of wild pollinators for pollination services may partially be offset by managed honey bees, compensating for the loss of wild pollinators $[3,7,8]$. This view, however, has recently been challenged

\footnotetext{
*Correspondence: hjxiao@jxau.edu.cn

${ }^{3}$ Institute of Entomology, Jiangxi Agricultural University,

Nanchang 330045, China

Full list of author information is available at the end of the article
}

after assessing the contribution of wild bees, hoverflies, butterflies, moths, wasps and beetles $[9,10]$.

The vast majority of the studies focussing on the interplay between wild and managed pollinators in providing agricultural pollination services originates from Europe and North America, where industrialization of agriculture has resulted in agroecosystems dominated by monocultures in large fields. In contrast, Chinese agroecosystems, particular in South China, are characterised by relatively small fields, leading to a high heterogeneity in terms of crop species, field management and field edges [11]. This high heterogeneity may favour wild pollinators by providing nesting sites and floral resources $[12$, 13]. We therefore expect that the small-holder agroecosystems in China support a high abundance and diversity of wild pollinators contributing to pollination services 
that significantly exceed the contribution of managed pollinators.

A globally important crop benefitting from pollination services is oilseed rape (Brassica napus L.), of which China is one of the world's largest producers with more than 7.5 million ha cultivated area for the production of cooking oil, feed and biofuel [14]. Although oilseed rape is considered a self-pollinating plant species [15], insect pollination can further increase yield and quality $[3,7,8$, 16]. Seed yield of individual oilseed rape plants is determined by the number of seeds per pod (seed set), the number of pods per plant (fruit set), and the individual seed weight. Seed set is mainly determined by the amount of pollen grains deposited on the stigma of flowers during the receptive period [17], which can be increased by pollinator-mediated pollen transfer [18]. Similarly, pollination usually enhances fruit set, i.e. the proportion of flowers developing into pods $[19,20]$. Oilseed rape plants show variation in their ability to compensate for a pollination deficit, which may depend on the cultivar [21-23] and the pollination efficiency of flower visiting insects $[8$, 24-26]. However, the potential to compensate for pollination deficit by allocating resources into heavier seeds or increased flowering has received little attention [but see 23, 27], but may have important consequences for the oilseed rape production potential in situations of pollinator declines.

The aim of this study is twofold. First, to assess the relationship between pollinator communities and oilseed rape yield parameters. We hypothesise that yield parameters will be positively influenced by more abundant and more diverse pollinator communities. Second, to assess the relative contribution of wild pollinators versus honey bees to oilseed rape pollination. Here, we expect that yield of oilseed rape is positively associated with the abundance of both wild pollinators and honey bees.

\section{Methods}

\section{Study area}

We selected 18 oilseed rape fields across a large geographical area in Jiangxi Province, China (N28.35 ${ }^{\circ}$ $\left.\mathrm{N} 28.99^{\circ}, \quad \mathrm{E} 115.26^{\circ}-\mathrm{E} 115.82^{\circ}\right)$. The mean distance between fields was $36.9 \mathrm{~km}$ (range: $5.8-75.2 \mathrm{~km}$ ). As the maximum foraging range of most pollinator species is less than $2 \mathrm{~km}[28,29]$, individual pollinators are unlikely to visit more than one field, and hence the pollinator communities in the study fields can be considered independent. The mean size of study fields was $845 \pm 86 \mathrm{~m}^{2}$ (range: $400-1400 \mathrm{~m}^{2}$ ) and all fields were sown between the middle and the end of October 2014 with the same traditional open-pollinated winter oilseed rape cultivar YangGuang-2009.

\section{Experimental design and plant yield parameters}

In the centre of each field, eight oilseed rape plants at a similar growth stage were selected, spaced $4 \mathrm{~m}$ apart. Each plant was covered by an individual cage (alternating open and closed). Closed cages had a base of $0.6 \times 0.6 \mathrm{~m}^{2}$, a height of $2.0 \mathrm{~m}$ and were entirely covered with $1 \times 1 \mathrm{~mm}^{2}$ mesh to exclude pollinators. This mesh size has only a limited influence on the microclimate in the cage [30]. The open cage was set as a control treatment and consisted of a similar frame as the closed cage, but only contained mesh at the roof and the top $0.3 \mathrm{~m}$ such that pollinators had access to the plants. This resulted in a similar shading of plants in closed and open cages. Neighbouring plants were removed to provide space for setting up cages, and the cages were established about one week before blooming and were removed during harvest.

After harvest, the number of pods and total number of flower stalks were counted for each plant. Seeds were removed from pods, weighed and counted using an automatic seed counter (SLY-C, Zhejiang Top Instrument, China). The following yield parameters were measured and calculated per plant: seed set (number of seeds per pod), number of pods (siliques) per plant, number of flowers per plant, fruit set (pod/flower ratio), seed weight (total seed weight divided by the total number of seeds) and yield (total weight of all seeds). Plants were dried for 30 days in the greenhouse and the total aboveground dry vegetative biomass excluding seeds and pods (referred to as straw) was assessed.

\section{Insect sampling}

The pollinator community in each experimental oil seed rape field was sampled by pan traps, which is a suitable method for sampling pollinators such as bees [31], hoverflies [32] and butterflies [33]. Each pan trap station consisted of three cups $(8.3 \mathrm{~cm}$ diameter, $13.5 \mathrm{~cm}$ height and a volume of $450 \mathrm{ml}$ ) fixed on a wooden stick at a distance of $1.5 \mathrm{~m}$ above the ground. The cups were white from the outside, and painted ultraviolet (UV) yellow, UV blue and UV white from the inside, respectively [34]. We used water saturated with kitchen salt $(\mathrm{NaCl})$ as a killing agent with several drops of detergent to break water surface tension. At $3 \mathrm{~cm}$ from the brim, two $3 \mathrm{~mm}$ diameter holes were drilled in order to drain off rainwater and sufficient water was added to prevent the traps from drying out. In each field, four stations were installed at the corners of a $20 \mathrm{~m} \times 20 \mathrm{~m}$ square in the centre of the field. Traps were set up before the onset of bloom, at the same time as the cages, and were monitored until harvest for a period ranging from 49 to 52 days. This difference in the sampling period was mainly caused by different trap establishment dates, 
but since the traps were established before the activity period of most pollinators, there was a negligible effect on the catch. Samples were collected five times at approximately 10-day intervals.

Insect pollinator specimens were collected and stored at $-20{ }^{\circ} \mathrm{C}$, and then sorted and pinned. All specimens were identified to species level when possible. Pollinator specimens were separated into wild pollinators (including wild bees, hoverflies, butterflies and moths, social and solitary wasps) and honey bees (Apis mellifera and Apis cerana). Asynchronous flowering times of the oilseed rape crops prevented the separation of insect communities that were visiting the oilseed fields during and after flowering (see flower cover data in Additional file 1). Therefore, all specimens collected from the same field were pooled in the analysis.

\section{Data analysis}

We conducted two main analyses. The first analysis focused on the effect of pollinator exclusion on plant yield parameters using linear mixed effect models. Response variables were calculated as the difference in plant yield parameters between plants with pollinator access (open cages) and plants without pollinator access (closed cages), and included (1) seed set, (2) number of pods per plant, (3) number of flowers per plant, (4) fruit set (pod/flower ratio), (5) thousand seed weight, (6) plant yield, (7) straw biomass, and (8) yield/straw ratio. Plant yield/straw ratio is the ratio between total seed weight and total dry vegetative biomass. It expresses the ratio of assimilates to seeds or vegetative growth, and provides a useful indicator for limitation in active seed sinks on the plant $[35,36]$ as a result of pollination deficit of oilseed rape. Treatment (closed cage versus open cage) was used as an explanatory variable (fixed factor) and study field as a random factor. Transformations were applied for response variables to meet normal distribution requirements.

The second analysis focused on the effect of pollinator abundance and diversity on yield parameters. Generalized linear mixed effect models were used with study field as a random factor. Data from the open and closed cage treatments were analysed separately. The purpose of the analysis on open cages was to assess the role of different pollinator taxa in pollination, while the analysis on closed cages was conducted to verify that pollinator abundance and community composition did not affect plant yield parameters in closed cages. Response variables included (1) seed set (Gaussian error distribution with identity-link function), (2) fruit set (gamma error distribution with log-link function), (3) thousand seed weight (gamma error distribution with log-link function), and (4) yield/straw ratio (gamma error distribution with log-link function). Explanatory variables included (a) wild pollinator abundance, (b) honey bee abundance, (c) wild pollinator diversity, and (d) plant straw biomass. Study field was included as a random factor. Wild pollinator diversity was characterised in terms of the back-transformed Shannon entropy index [37], the rarefied number of species $(n=54)$ [38] and the Fisher's alpha index [39]. As the back-transformed Shannon entropy index was strongly correlated with both the rarefied number of species (Pearson $\mathrm{r}=0.94, P<0.001$ ) and Fisher's alpha $(\mathrm{r}=0.91, P<0.001)$, and is a robust indicator for mobile insects and uneven sample sizes [40-42], we selected it as an indicator for pollinator diversity (with a focus on species richness) in the statistical analysis. Plant straw biomass was included as a control variable to account for variation in plant size, but was excluded for the analysis of yield/straw ratio.

All models were validated by checking residuals according to the protocol of Zuur et al. [43] and deviance residuals met normality and homoscedasticity assumptions. In addition, model residuals were checked for spatial autocorrelation using Moran's I coefficient [44]. No significant spatial autocorrelation was found in the fitted models $(P>0.05)$. All calculations and analyses were conducted in R (v3.1.2) [45] using the "nlme" package for linear mixed effect models [46], the "lme4" package for generalized linear mixed effect models [47], and the "ape" package for spatial autocorrelation [48]. Means and standard errors are reported throughout the paper.

\section{Results}

\section{Pollinator community}

A total of 5148 specimens representing 60 pollinator species were collected from the pan traps. These included 3931 Hymenoptera comprising 44 species, 52 hoverflies (7 species), and 1165 Lepidoptera (9 species). The top five most abundant species were cabbage butterfly (Pieris rapae), two wild bee species Eucera chinensis and Lasioglossum proximatum, and two honey bee species A. mellifera and A. cerana, accounting for 21.6, 20.8, $16.5,9.1$ and $8.1 \%$ of the overall specimens, respectively (see complete species list in Additional file 1). The overall abundance of collected wild pollinators across the 18 fields was $237( \pm 40)$ individuals, ranging from 54 to 720 individuals per field, while the abundance of honey bees averaged $49( \pm 12)$ individuals, ranging from 1 to 195 individuals per field, highlighting substantial betweenfield variation. This variation allows a meaningful analysis of the relationship between pollinator abundance and diversity on the one hand and plant yield parameters on the other. 


\section{Plant yield parameters}

Results indicated that pollinator exclusion significantly influenced plant yield parameters (Table 1). Oilseed rape plants in closed cages had 38\% $( \pm 4 \%)$ lower seed set, $17 \%$ $( \pm 4 \%)$ lower fruit set, $12 \%( \pm 14 \%)$ lower yield and $35 \%$ $( \pm 7 \%)$ lower yield/straw ratios than plants in open cages (Fig. 1). However, plants in the closed cage treatment had $22 \%( \pm 7 \%)$ higher seed weight, $28 \%( \pm 9 \%)$ more flowers, and $39 \%( \pm 11 \%)$ more straw biomass than plants in open cages. The number of pods per plant was not significantly different between treatments.

Table 1 Results of linear mixed effect models showing the effects of pollinator exclusion on oilseed rape yield parameters

\begin{tabular}{llllc}
\hline Response variable & Data transformation & df & \multicolumn{1}{l}{$\boldsymbol{t}$} & \multicolumn{1}{l}{$\boldsymbol{P}$} \\
\hline Seed set & None & 113 & 7.86 & $<0.001$ \\
Number of pods & Square root & 115 & -1.06 & 0.3 \\
Number of flowers & Square root & 115 & -2.99 & 0.003 \\
Fruit set & Arcsine & 115 & 4.26 & $<0.001$ \\
Thousand seed weight & Logarithm & 111 & -3.25 & 0.002 \\
Plant yield & Logarithm & 111 & 2.31 & 0.02 \\
Plant straw biomass & Square root & 115 & -3.72 & $<0.001$ \\
Yield/straw ratio & Square root & 111 & 5.21 & $<0.001$ \\
\hline
\end{tabular}

Negative $t$ values indicate a higher value for the plants with pollinator exclusion than for the plants with pollinator access

\section{Influence of pollinators on plant yield parameters}

When pollinators had access to oilseed rape plants, seed set was positively associated with wild pollinator abundance and diversity (Table 2). In addition, a strong positive association was observed between the yield/straw ratio and the abundance and diversity of wild pollinators. In contrast, the abundance of honey bees was not significantly associated with any of the plant yield parameters (Table 2). The control analysis using the data from the closed cage treatment did not reveal any significant effects of the abundance or diversity of pollinators on yield components, indicating that the exclusion treatment functioned well and confirming that associations between wild pollinators and yield components of oilseed rape in the open cages can indeed be attributed to insect pollination.

\section{Discussion}

The heterogeneous landscape mosaic in Southern China, which is characterized by small field sizes, harboured a rich pollinator community. Accordingly, wild pollinators contributed substantially to oilseed rape yield, confirming our expectations. The fact that we did not find statistical support for the contribution of honey bees to oilseed rape yield parameters, despite their well-documented contribution crop pollination in other parts of the world, substantiates the relevance of natural service providers to small-holder farming.
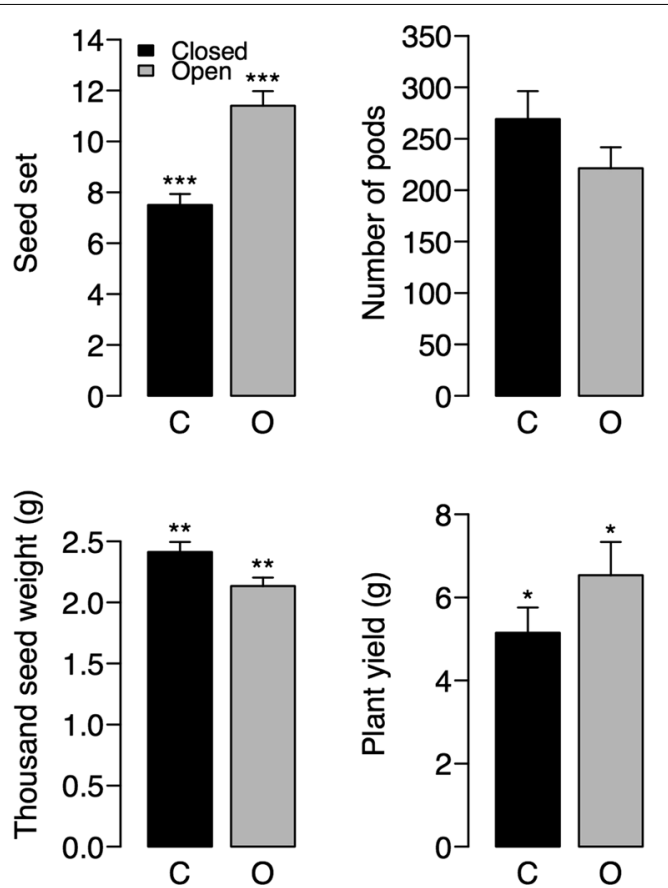
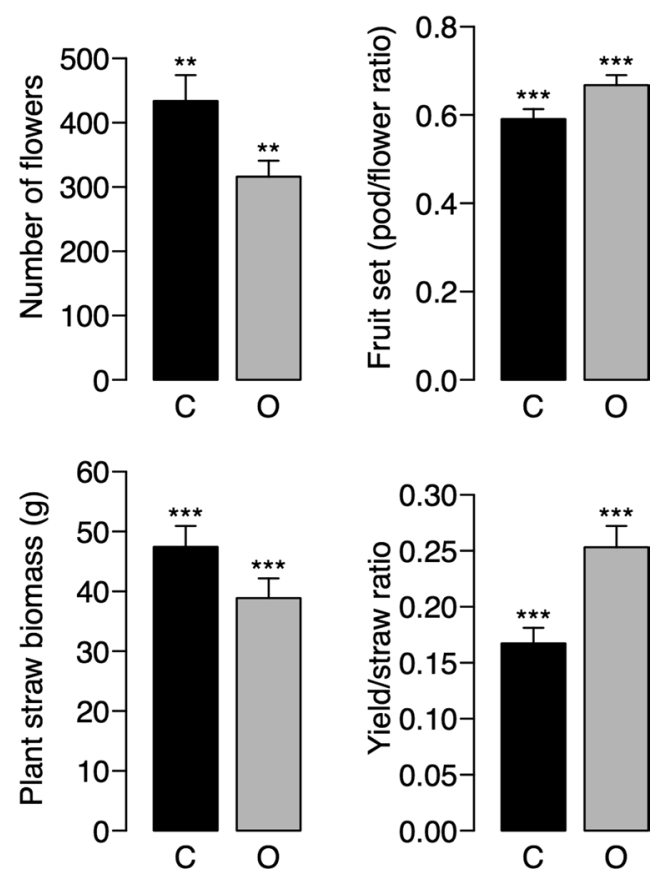

Fig. 1 Plant yield parameters of oilseed rape plants in closed $(C)$ and open $(O)$ cages. Bars represent SEM. Asterisks show the significance level based on an analysis with mixed models (see Table $2 ;^{*} \leq 0.05 ;{ }^{* *} \leq 0.01 ;{ }^{* * *}<0.001$ ) 
Table 2 Results of generalized linear mixed effect models showing the relationship between plant yield parameters and pollinator variables for oilseed rape plants with pollinator access (open cage)

\begin{tabular}{llllll}
\hline Response variable & Error distribution & Straw biomass & Wild pollinator abundance & Wild pollinator diversity & Honey bee abundance \\
\cline { 3 - 5 } Seed set & Gaussian & - & $0.015 \pm 0.007^{*}$ & $0.801 \pm 0.352^{*}$ & - \\
Fruit set & Gamma & - & - & - & - \\
Seed weight & Gamma & - & - & - & - \\
Yield/straw ratio & Gamma & $/$ & $0.003 \pm 0.001^{* * *}$ & $0.159 \pm 0.053^{* *}$ & - \\
\hline
\end{tabular}

Values indicate estimates and standard errors, a dash (-) indicates that the variable was not significant, a slash (/) indicates that the variable was not entered in the model because of dependency on the response variable, and asterisks show significance levels $\left({ }^{*} \leq 0.05 ;{ }^{* *} \leq 0.01 ;{ }^{* * *}<0.001\right)$

We identified 60 insect pollinator species, 44 of which were Hymenoptera species. This represents a high number of pollinator species in comparison with other landscape-scale studies in oilseed rape. For example, 20 species (honeybees, bumblebees and solitary bees) from 1181 individuals were reported in Wiltshire, UK [49], 36 flowervisiting species from 1866 individuals Uppsala, Sweden [3], and 26 bee and hoverfly species in Ireland (number of individuals was not mentioned) [8]. Our findings were in line with our expectation that the study region contains a high diversity of wild pollinators, which may partly due to the high heterogeneity in field size, crop species and crop management, and high diversity of wild plant species in field edges in small-holder agroecosystems [11].

Insect pollinated plants showed higher seed set and overall higher yields than plants deprived from pollinators. Therefore, our study contributes to a body of evidence that insect pollination matters for oilseed production despite its capacity for self-pollination [3, 21, 50-52]. At the same time, insect pollination lowered some yield parameters such as seed weight, suggesting compensation mechanisms of the plants also in line with previous studies [19, 21]; but see Bommarco et al. [53]. Often, plants with a pollination deficit produce fewer seeds per pod, but each seed then receives a higher share of the plant assimilates [19, 21, 52, 53]. The higher number of flowers on plants in closed as compared to open cages provides further support for compensatory responses to a pollination deficit [23].

The higher straw biomass of oilseed rape plants in closed cages points to an increased allocation of assimilates to the above ground vegetative plant parts, which supports a lack of sink strength resulting from a pollination deficit. The positive effect of pollinator exclusion on straw weight may also in part be due to the high energetic cost of producing fatty acids in seeds as compared to the lower energetic conversion costs to leaf and stem dry matter [54]. Overall, compensation effects did not fully counterbalance the yield loss due to the lack of pollination as exemplified by the $12 \%$ higher yield when comparing plants with pollinator access to plants without pollinator access.
Wild pollinator abundance and diversity were positively associated with oilseed rape seed set and yield/ straw ratio, but not with fruit set and seed weight, suggesting that their benefits to oilseed rape yield per plant mostly result from an increased number of seeds per pod. The control analysis, which showed no relationship between plant yield parameters and pollinator abundance and diversity for closed cages, confirmed the effectiveness of the exclusion treatment and the overall consistency of the experimental setup. This also suggested that pollinator collections from pan traps can be used as a proxy in reflecting the pollinator communities and pollination service at the landscape scale $[55,56]$.

We assessed the contribution of insect pollination on isolated plants where neighbouring plants were removed. The focus on isolated plants may have also resulted in an reduction of plant-to-plant pollen transfer [35] and a reduction in plant competition for water, nutrients and light. Therefore, we may underestimate the potential of closed oil seed rape stands to compensate for pollinator limitation by mechanical and wind pollination $[35,57]$ and refrain from estimating agronomic benefits at the field level [22]. Furthermore, the mesh tents may have reduced wind pollination, even though the same mesh size has been widely applied in pollinator exclusion studies $[3,16,19,53]$.

Surprisingly, our analysis gave no support for the contribution of honey bees to oilseed rape yield, even though there were large differences in honey bee abundance between fields. While the contribution of honey bees to crop pollination is widely documented [see review in 58], this result is in line with a current global meta-analysis that highlighted the importance of wild pollinators in crop pollination [9]. In our study, the higher contribution of wild pollinators to crop pollination can in part be attributed to their five times higher abundance as compared to honey bees. Indeed, wild pollinators dominate pollinator communities in many agroecosystems [59]. The relative low number of honey bees may have resulted from a relatively low density of bee hives in the study areas. Also, some wild pollinator species may be as efficient or even more efficient than honey bees [24, 26]. In 
our case, the abundant cabbage butterfly (Pieris rapae) might be an important pollinator [60]. As their larvae are considered a pest, however, this species may have both a positive and negative effect on oilseed rape production.

\section{Conclusion}

Our study demonstrates that wild pollinators play an important role in the pollination of oilseed crops in small-holder farming systems in China. Wild pollinator abundance and diversity contribute to oilseed rape yield by mediating increased allocation to seeds rather than above-ground straw biomass, but oilseed rape plants suffering from a pollination deficit can compensate to some extent by generating heavier seeds, more flowers and higher straw biomass. This study highlights the importance of conserving wild pollinators in order to maximise oilseed rape production, especially in heterogeneous landscapes where their pollination service is exceeding the service provided by managed pollinators.

\section{Additional file}

Additional file 1. Raw data on plant yield components, pollinator abundance and pollinator names.

\section{Authors' contributions}

$Y Z, H X, F J J A B, F J$ and WW designed the experiments. YZ, HX and SL performed the experiments. $Y Z$ analysed the data. YZ, FJJAB and WW wrote the manuscript; other authors provided editorial advice. All authors read and approved the final manuscript.

\footnotetext{
Author details

${ }^{1}$ Centre for Crop Systems Analysis, Wageningen University, P.O. Box 430, 6700 AK Wageningen, The Netherlands. ${ }^{2}$ Present Address: Department of Environmental Science, Xi'an Jiaotong-Liverpool University, Suzhou 215123, China. ${ }^{3}$ Institute of Entomology, Jiangxi Agricultural University, Nanchang 330045, China. ${ }^{4}$ Farming Systems Ecology, Wageningen University, P.O. Box 430, 6700 AK Wageningen, The Netherlands. ${ }^{5}$ Department of Animal Ecology, Justus Liebig University, Heinrich-Buff-Ring 26-32, 35932 Giessen, Germany. ${ }^{6}$ Institute of Apicultural Research, Chinese Academy of Agricultural Sciences, Beijing 100093, China.
}

\section{Acknowledgements}

We thank Mario van Telgen, Junhui Chen, Chao Zou, Yuekun Wu and Weizhao Sun for help in the fieldwork. We also thank Huanli Xu for helping with pollinator identification.

\section{Competing interests}

The authors declare that they have no competing interests.

\section{Availability of data and materials}

The data sets supporting the results are included within the article and its Additional file 1.

\section{Ethics}

Pollinators in this study did not involve regulated invertebrates.

\section{Funding}

This study was funded by the Division for Earth and Life Sciences of the Netherlands Organization for Scientific Research (Grant 833.13.004), the National Natural Science Foundation of P.R. China (31360461), the Agricultural Science and Technology Innovation Program (CAAS-ASTIP-2015-IAR) and the Cultivation Plan for Young Scientists of Jiangxi Province (20153BCB23014).

Received: 26 July 2016 Accepted: 5 February 2017

Published online: 21 February 2017

\section{References}

1. Klein A-M, Vaissiere BE, Cane JH, Steffan-Dewenter I, Cunningham SA, Kremen C, Tscharntke T. Importance of pollinators in changing landscapes for world crops. Proc R Soc B. 2007;274(1608):303-13.

2. Allen-Wardell G, Bernhardt P, Bitner R, Burquez A, Buchmann S, Cane J, Cox PA, Dalton V, Feinsinger P, Ingram M, et al. The potential consequences of pollinator declines on the conservation of biodiversity and stability of food crop yields. Conserv Biol. 1998;12(1):8-17.

3. Bommarco R, Marini L, Vaissiere BE. Insect pollination enhances seed yield, quality, and market value in oilseed rape. Oecologia. 2012;169(4):1025-32.

4. Biesmeijer JC, Roberts SPM, Reemer M, Ohlemüller R, Edwards M, Peeters T, Schaffers AP, Potts SG, Kleukers R, Thomas CD, et al. Parallel declines in pollinators and insect-pollinated plants in Britain and the Netherlands. Science. 2006;313(5785):351-4.

5. Potts SG, Biesmeijer JC, Kremen C, Neumann P, Schweiger O, Kunin WE. Global pollinator declines: trends, impacts and drivers. Trends Ecol Evol. 2010;25(6):345-53.

6. Gill RJ, Baldock KCR, Brown MJF, Cresswell JE, Dicks LV, Fountain MT, Garratt MPD, Gough LA, Heard MS, Holland JM, et al. Protecting an ecosystem service: approaches to understanding and mitigating threats to wild insect pollinators. Adv Ecol Res. 2016;54:135-206.

7. Sabbahi R, De Oliveira D, Marceau J. Influence of honey bee (Hymenoptera: Apidae) density on the production of canola (Crucifera: Brassicacae). J Econ Entomol. 2005;98(2):367-72.

8. Stanley DA, Gunning D, Stout JC. Pollinators and pollination of oilseed rape crops (Brassica napus L.) in Ireland: ecological and economic incentives for pollinator conservation. J Insect Conserv. 2013;17(6):1181-9.

9. Garibaldi LA, Steffan-Dewenter I, Winfree R, Aizen MA, Bommarco R, Cunningham SA, Kremen C, Carvalheiro LG, Harder LD, Afik O, et al. Wild pollinators enhance fruit set of crops regardless of honey bee abundance. Science. 2013;339(6127):1608-11.

10. Rader R, Bartomeus I, Garibaldi LA, Garratt MPD, Howlett BG, Winfree R, Cunningham SA, Mayfield MM, Arthur AD, Andersson GKS, et al. Non-bee insects are important contributors to global crop pollination. PNAS. 2016;113(1):146-51.

11. Liu Y, Duan M, Yu Z. Agricultural landscapes and biodiversity in China. Agric Ecosyst Environ. 2013;166:46-54

12. Benton TG, Vickery JA, Wilson JD. Farmland biodiversity: is habitat heterogeneity the key? Trends Ecol Evol. 2003;18(4):182-8.

13. Fahrig L, Baudry J, Brotons L, Burel FG, Crist TO, Fuller RJ, Sirami C, Siriwardena GM, Martin JL. Functional landscape heterogeneity and animal biodiversity in agricultural landscapes. Ecol Lett. 2011;14(2):101-12.

14. FAO. FAOSTAT; 2013. http://faostat3.fao.org. Accessed 1 Jan 2017.

15. Williams IH, Martin AP, White RP. The pollination requirements of oil-seed rape (Brassica napus L.). J Agric Sci. 1986;106(01):27-30.

16. Jauker F, Wolters $V$. Hover flies are efficient pollinators of oilseed rape. Oecologia. 2008;156(4):819-23.

17. Pechan PM. Ovule fertilization and seed number per pod determination in oil seed rape (Brassica napus). Ann Bot. 1988;61(2):201-7.

18. Abrol DP. Honeybees and rapeseed: a pollinator-plant interaction. Adv Bot Res. 2007:45:337-67.

19. Steffan-Dewenter I. Seed set of male-sterile and male-fertile oilseed rape (Brassica napus) in relation to pollinator density. Apidologie. 2003;34(3):227-35.

20. Jauker F, Bondarenko B, Becker HC, Steffan-Dewenter I. Pollination efficiency of wild bees and hoverflies provided to oilseed rape. Agric For Entomol. 2012;14(1):81-7.

21. Hudewenz A, Pufal G, Bögeholz A-L, Klein A-M. Cross-pollination benefits differ among oilseed rape varieties. J Agric Sci. 2014;152(5):770-8. 
22. Lindström SAM, Herbertsson L, Rundlöf M, Smith HG, Bommarco R. Large-scale pollination experiment demonstrates the importance of insect pollination in winter oilseed rape. Oecologia. 2016;180(3):759-69.

23. Marini L, Tamburini G, Petrucco-Toffolo E, Lindström SAM, Zanetti F, Mosca G, Bommarco R. Crop management modifies the benefits of insect pollination in oilseed rape. Agric Ecosyst Environ. 2015;207:61-6.

24. Holzschuh A, Dudenhöffer J-H, Tscharntke T. Landscapes with wild bee habitats enhance pollination, fruit set and yield of sweet cherry. Biol Conserv. 2012;153:101-7.

25. Hoyle M, Cresswell JE. The effect of wind direction on cross-pollination in wind-pollinated GM crops. Ecol Appl. 2007;17(4):1234-43.

26. Rader R, Howlett BG, Cunningham SA, Westcott DA, Newstrom-Lloyd LE, Walker MK, Teulon DA, Edwards W. Alternative pollinator taxa are equally efficient but not as effective as the honeybee in a mass flowering crop. J Appl Ecol. 2009;46(5):1080-7.

27. Sutter L, Albrecht M. Synergistic interactions of ecosystem services: florivorous pest control boosts crop yield increase through insect pollination. Proc R Soc B. 1824;2016:283.

28. Chifflet R, Klein EK, Lavigne C, Le Feon V, Ricroch AE, Lecomte J, Vaissiere BE. Spatial scale of insect-mediated pollen dispersal in oilseed rape in an open agricultural landscape. J Appl Ecol. 2011;48(3):689-96.

29. Steffan-Dewenter I, Munzenberg U, Burger C, Thies C, Tscharntke T. Scale-dependent effects of landscape context on three pollinator guilds. Ecology. 2002;83(5):1421-32.

30. Martin EA, Reineking B, Seo B, Steffan-Dewenter I. Natural enemy interactions constrain pest control in complex agricultural landscapes. PNAS. 2013;110(14):5534-9.

31. Cane JH, Minckley RL, Kervin LJ. Sampling bees (Hymenoptera: Apiformes) for pollinator community studies: pitfalls of pan-trapping. J Kans Entomol Soc. 2000;73(4):225-31.

32. Irvin NA, Wratten SD, Frampton CM, Bowie MH, Evans AM, Moar NT. The phenology and pollen feeding of three hover fly (Diptera: Syrphidae) species in Canterbury, New Zealand. NZ J Zool. 1999;26(2):105-15.

33. Cizek O, Bakesová A, Kuras T, Benes J, Konvicka M. Vacant niche in alpine habitat: the case of an introduced population of the butterfly Erebia epiphron in the Krkonoše Mountains. Acta Oecol. 2003;24(1):15-23.

34. Fortel L, Henry M, Guilbaud L, Guirao AL, Kuhlmann M, Mouret H, Rollin O, Vaissiere BE. Decreasing Abundance, Increasing Diversity and changing structure of the wild bee community (Hymenoptera: Anthophila) along an urbanization gradient. PLoS ONE. 2014;9(8):e104679.

35. Diepenbrock W. Yield analysis of winter oilseed rape (Brassica napus L.): a review. Field Crops Res. 2000;67(1):35-49.

36. Iglesias FM, Miralles DJ. Changes in seed weight in response to different sources: sink ratio in oilseed rape. IJARIT. 2014:4(1):44-52.

37. Jost L. Entropy and diversity. Oikos. 2006;113(2):363-75.

38. Hurlbert SH. The nonconcept of species diversity: a critique and alternative parameters. Ecology. 1971;52(4):577-86.

39. Fisher RA, Corbet AS, Williams CB. The relation between the number of species and the number of individuals in a random sample of an animal population. J Anim Ecol. 1943;12(1):42-58.

40. Fiedler K, Truxa C. Species richness measures fail in resolving diversity patterns of speciose forest moth assemblages. Biodivers Conserv. 2012;21(10):2499-508.

41. Beck J, Schwanghart W. Comparing measures of species diversity from incomplete inventories: an update. Methods Ecol Evol. 2010;1(1):38-44.

42. Jost L. Partitioning diversity into independent alpha and beta components. Ecology. 2007:88(10):2427-39.
43. Zuur A, leno EN, Walker N, Saveliev AA, Smith GM. Mixed effects models and extensions in ecology with R. Stanford: Springer Science \& Business Media; 2009

44. Gittleman JL, Kot M. Adaptation: statistics and a null model for estimating phylogenetic effects. Syst Zool. 1990;39:227-41.

45. R Core Team. R: A language and environment for statistical computing. Vienna: R Foundation for Statistical Computing; 2015. p. 2014

46. Pinheiro J, Bates D, DebRoy S, Sarkar D, R Core Team: nlme: linear and nonlinear mixed effects models. R package version 31-118. 2014.

47. Bates D, Maechler M, Bolker B, Walker S. Ime4: Linear mixed-effects models using Eigen and S4. R package version 11-7. 2014.

48. Paradis E, Claude J, Strimmer K. APE: analyses of phylogenetics and evolution in R language. Bioinformatics. 2004;20(2):289-90.

49. Woodcock BA, Edwards M, Redhead J, Meek WR, Nuttall P, Falk S, Nowakowski M, Pywell RF. Crop flower visitation by honeybees, bumblebees and solitary bees: behavioural differences and diversity responses to landscape. Agric Ecosyst Environ. 2013;171:1-8.

50. Bartomeus I, Potts SG, Steffan-Dewenter I, Vaissiere BE, Woyciechowski M, Krewenka KM, Tscheulin T, Roberts SP, Szentgyörgyi H, Westphal C. Contribution of insect pollinators to crop yield and quality varies with agricultural intensification. PeerJ. 2014;2:e328.

51. Mishra RC, Kumar J, Gupta JK. The effect of mode of pollination on yield and oil potential of brassica campestris L. var. Sarson with observations on insect pollinators. J Apic Res. 1988;27(3):186-9.

52. Free JB, Nuttall PM. The pollination of oilseed rape (Brassica napus) and the behaviour of bees on the crop. J Agric Sci. 1968;71(01):91-4.

53. Durán XA, Ulloa RB, Carrillo JA, Contreras JL, Bastidas MT. Evaluation of yield component traits of honeybee pollinated (Apis mellifera L.) Rapeseed canola (Brassica napus L.). Chilean. J Agric Res. 2010;70(2):309-14.

54. Penning de Vries FWT, van Laar HH. Simulation of growth processes and the model BACROS. In: Penning de Vries FWT, van Laar HH, editors. Simulation of plant growth and crop production. Wageningen: Pudoc; 1982. p. 114-35.

55. Westphal C, Bommarco R, Carré G, Lamborn E, Morison N, Petanidou T, Potts SG, Roberts SPM, Szentgyörgyi H, Tscheulin T. Measuring bee diversity in different European habitats and biogeographical regions. Ecol Monogr. 2008;78(4):653-71.

56. Kovacs-Hostyanszki A, Haenke S, Batary P, Jauker B, Baldi A, Tscharntke T, Holzschuh A. Contrasting effects of mass-flowering crops on bee pollination of hedge plants at different spatial and temporal scales. Ecol Appl. 2013;23(8):1938-46.

57. Angadi SV, Cutforth HW, McConkey BG, Gan Y. Yield adjustment by Canola grown at different plant populations under semiarid conditions. Crop Sci. 2003;43(4):1358-66.

58. Thapa R. Honeybees and other insect pollinators of cultivated plants: a review. J Inst Agri Anim Sci. 2006;27:1-23.

59. Kleijn D, Winfree R, Bartomeus I, Carvalheiro LG, Henry M, Isaacs R, Klein A-M, Kremen C, M'Gonigle LK, Rader R, et al. Delivery of crop pollination services is an insufficient argument for wild pollinator conservation. Nat Commun. 2015;6:7414.

60. Conner JK, Davis R, Rush S. The effect of wild radish floral morphology on pollination efficiency by four taxa of pollinators. Oecologia. 1995:104(2):234-45. 